\title{
Diffused Reflectance Spectroscopy for Characterization of Salt-Affected Soil (SAS) Attributes
}

\author{
Arijit Barman ${ }^{*}$ and Rajeev Srivastava ${ }^{1}$ \\ ICAR-Central Soil Salinity Research Institute, Karnal- 132 001, Haryana, India \\ ${ }^{\prime}$ ICAR-National Bureau of Soil Survey and Land Use Planning, Nagpur- 440 033, Maharashtra, India
}

\begin{abstract}
Identification of soil salinity based on traditional methods (measurement in saturation extract) required time, labour and capital, whereas, ground based nonimaging hyperspectral remote sensing estimates the soil salinity and alkalinity parameters within limited resources and can be used for real time monitoring purpose. Laboratory experiment was conducted to study the spectral properties using VNIR spectroscopy in silt loam and silty clay loam soil saturated with different levels of chloride, sulphate and carbonate of sodium salts. Salinity absorption features were more pronounced around $1900 \mathrm{~nm}$, followed by 1400 and $2200 \mathrm{~nm}$. The salt concentration was inversely related to reflectance values in saline soils. Wavelength was shifted from $1900 \mathrm{~nm}$ to higher wavelength value and this shifting feature was also correlated with the increase in salt concentration. Relatively high correlation coefficients of $\mathrm{EC}_{\mathrm{e}}$, saturated extract $\mathrm{Na}^{+}$and $\mathrm{Cl}^{-}$with soil reflectance values were found in between 1420 to $2020 \mathrm{~nm}$ than other soil properties. Increased use and application of VNIR for salt-affected soil would help establish a detailed spectral library through captured signature in sodium salt saturated soil.
\end{abstract}

Key words: Salt-affected soils, hyperspectral remote sensing, regression model

\section{Introduction}

Soil salinization and alkalinisation are the most common problems of cultivated lands in arid and semiarid regions of India. Intensive cultivation of land for agricultural production with poor quality of groundwater causes the expansion of area under saltaffected soils (SAS). Increase in the concentrations of carbonate and bicarbonate anions along with sodium cation lead to soil sodicity resulting in yield reduction (Metternicht and Zinck 2003), particularly in the foodgrowing regions of the Indo-Gangetic plains (IGP).

*Corresponding author: (Email: arijitbarman1988@gmail.com)
Timely identification and monitoring of SAS are important for arresting the soil salinization (Sinha et al. 2017). The conventional method for identifying SAS is laborious, expensive and require intensive sampling to cover a large area (Shepherd and Walsh 2002), whereas, VNIR spectroscopy is a rapid non-destructive technique, makes easy to cover a wide range of areas.

Reflectance spectroscopy uses the physics of the atomic and molecular vibration process, which causes the absorption features in salts, evaporate minerals and soil spectra (Csillag et al. 1993; Metternicht and Zink 1997; Ben-Dor et al. 1999). These features are more pronounced in the middle infrared 
bands with water and $\mathrm{OH}^{-}$absorption features which allow distinction of soil surfaces affected by $\mathrm{Cl}^{-}$and $\mathrm{SO}_{4}^{2-}$ salts (Howari et al. 2000). This information is used to establish a statistical relationship between spectral properties of salt-affected soils and the various amounts of salts in soil (Farifteh et al. 2004). Multiple Linear Regression (Chang et al. 2001; Farifteh et al. 2007; Volkan et al. 2010) model and other data mining techniques (Brown et al. 2006) have been applied for interpreting the relationships between soil reflectance spectra and various soil properties including salinity. The MLR technique gives acceptable results between salt concentration and measured reflectance spectra over other complex spectral modelling procedure (Farifteh et al. 2007).

However, these statistical relations of salt content with the spectrum is region-specific, discrimination of different degree of salinization can be possible if the spectral characteristics of saline soil's spectrum and the underlying factors are examined based on locally developed hyperspectral models. In this regard, more and more research should be directed towards the analysis of soil reflectance spectra of the major food growing areas suffering from different degree of salinity and sodicity as that of the IGP plains of Haryana. This paper aims to explore the development of a laboratory-based hyperspectral model for soil salinity assessment in the salt-affected soils of IGP areas of Haryana, India using VNIR reflectance spectroscopy through simple MLR technique.

\section{Materials and Methods}

Soil sampling

Surface soil samples $(0-15 \mathrm{~cm})$ of silty clay loam (Soil-1) with $\left(76^{\circ} 57^{\prime} 04.5^{\prime \prime} \mathrm{E} ; 2^{\circ} 42^{\prime} 32.9^{\prime \prime} \mathrm{N}\right)$ and silt loam (Soil-2) with (7609'42.5” E; 28 $\left.09^{\circ} 18.8^{\prime \prime} \mathrm{N}\right)$ were collected from the research farm of CSSRI, Karnal district of Haryana state just after the harvest of wheat of rice-wheat cropping system. Then a controlled laboratory experiment was used to investigate the relationships between reflectance spectra and soil salinity.

\section{Controlled laboratory experiment}

The collected soil samples (reclaimed sodic soil) were air-dried, crushed and sieved through 2-mm sieve by following the procedure described by Van (1993). Subsequently, the soil sample was saturated artificially with three main types of salts, viz., chloride, sulphate and carbonate of Sodium (99\% purity) and a mixture of these salts with six levels (percentage by weight), ranging from non-salinity to high salinity $(0.2$, $0.5,1,2,5$ and $10 \%)$. After saturation, excess water was allowed to drain. The treated samples were air-dried and processed. In this way, total 148 samples (soil type-2; salt type-4 (3 types of salts and their mixture); salt level-6; replication-3 and control-4 (2 control from each soil type)) of different levels of soil salinity were artificially created. Before soil analysis, we have taken hyperspectral reflectance by Spectroradiometer. We have considered 98 samples for calibration and 48 samples for validation in MLR analysis.

\section{Soil analysis}

A total of 148 samples were air-dried, crushed and passed through a $2 \mathrm{~mm}$ sieve and analyzed for $\mathrm{EC}_{\mathrm{e}}$, $\mathrm{pH}_{\mathrm{s}}, \mathrm{Na}^{+}, \mathrm{K}^{+}, \mathrm{Mg}^{2+}, \mathrm{Ca}^{2+}, \mathrm{CO}_{3}^{2-}, \mathrm{HCO}_{3}^{-}, \mathrm{Cl}^{-}$and $\mathrm{SO}_{4}^{2-}$ following standard laboratory techniques (Van 1993). Soil electrical conductivity $\left(\mathrm{EC}_{\mathrm{e}}\right)$ and $\mathrm{pH}_{\mathrm{s}}$ were measured in the saturated soil extract. Exchangeable cations $\mathrm{Ca}^{2+}$ and $\mathrm{Mg}^{2+}$ (Cheng and Bray 1951), $\mathrm{Na}^{+}, \mathrm{K}^{+}$ and anions $\mathrm{CO}_{3}^{2-}, \mathrm{HCO}_{3}^{-}, \mathrm{Cl}^{-}$(Richards 1954) and $\mathrm{SO}_{4}{ }^{2-}$ (Chesnin and Yien 1950) were determined in the saturation extract.

\section{Hyperspectral reflectance data acquisition}

Soil diffuse reflectance spectra were recorded for each soil sample using a Field Spec Pro FR Spectroradiometer (Analytical Spectral Devices Inc., Boulder, Colorado) at wavelengths ranging from 350 to $2500 \mathrm{~nm}$ with a narrow spectral sampling interval of 1 $\mathrm{nm}$. Samples were illuminated from above with two tungsten quartz halogen filament lamps in housings with aluminium reflectors (Lowel pro-lamp, Lowel-Light 
Manufacturer Inc., New York, NY) with 50W bulb; $3200 \mathrm{~K}$ colour temperature (Welch Allyn, Skaneateles Falls, NY). The reflected light was collected with a $25^{\circ}$ field-of-view fore-optic that was kept vertically at a distance of $5 \mathrm{~cm}$ above the sample. Air-dried soil samples subjected to a pass-through $2 \mathrm{~mm}$ sieve were packed in $23 \mathrm{~mm}$ deep, 55-mm diameter black polypropylene dishes. Air-dried soils were used to minimize the effects of variation in soil moisture on reflectance. The over-filled dishes were scrapped-off by a blade to ensure a flat surface flush with the top of the dish. An average of three spectra was recorded for each soil sample to minimize instrument signal to noise ratio. Before recording soil sample reflectance, white reference spectra were recorded using calibrated spectral on (Labsphere, Sutton, NH) placed at the same distance from the fore-optic as those of soil samples for standardization. Reflectance readings for each wavelength band were expressed relative to the average of the spectral on readings. Variation in overall spectral shape among soil samples was studied by plotting the relative reflectance values against different wavebands.

\section{Data processing and transformation}

The original spectra consisting of relative reflectance values of 2151 points (at $1 \mathrm{~nm}$ interval) between 350 and $2500 \mathrm{~nm}$ were weighted averaged at every tenth-nanometer wavelength interval by integration technique as described by Srivastava et al. (2015). The integrated value of soil reflectance at every tenth-nanometer wavelength $(360,370,380, \ldots, 2490$ $\mathrm{nm}$ ) was determined by the following equation: $\mathrm{IR}=$

$$
\mathrm{r}^{2}=1-\left(\frac{\sum_{i}^{n}\left(Y_{\text {pred }}-Y_{\text {meas }}\right)^{2}}{\sum_{i}^{n}\left(Y_{i}-Y_{\text {mean }}\right)^{2}}\right)
$$

$\mathrm{RMSEP}=\sqrt{\frac{\sum_{i}^{n}\left(Y_{\text {pred }}-Y_{\text {meas }}\right)^{2}}{n-1}}$

$$
\mathrm{RPD}=\mathrm{SD}_{\mathrm{val}} / \mathrm{RMSEP}
$$

where: $Y_{\text {pred }}$-predicted values; $Y_{\text {mean }}$-mean of measured values, $\mathrm{Y}_{\text {meas }}$-measured values; $\mathrm{n}$ number of predicted/measured values with $\mathrm{i}-1,2, \ldots \ldots . \mathrm{n} ; \mathrm{SD}_{\text {val. }}{ }^{-}$ standard deviation of measured values in the validation set; and RMSEP $=$ root mean square error of prediction of validation dataset.

\section{Results and Discussion \\ Chemical composition of salt-affected soils}

The statistical parameters of the soil chemical properties of the processed soil samples studied under laboratory conditions are given in table 1 . The data indicate that soil $\mathrm{pH}$ varies between 6.9 and 10.0 and the majority of the samples (over $75 \%$ ) have a soil $\mathrm{pH}$ less than 8.0. The $\mathrm{EC}_{\mathrm{e}}$ values vary from 0.96 to $130.7 \mathrm{dS} \mathrm{m}^{-1}$ and nearly $75 \%$ of the samples have $\mathrm{EC}_{\mathrm{e}}$ values of 56.3 $\mathrm{dS} \mathrm{m}^{-1}$. This indicates that the majority of the soil samples in this study are of very strong saline. One-fourth of the total samples have $\mathrm{EC}_{\mathrm{e}}$ values of $7.1 \mathrm{dS} \mathrm{m}^{-1}$ in slightly saline range. Among the cations, average $\mathrm{Na}^{+}$ concentration $(1.1 \%)$ is highest, followed by $\mathrm{Ca}^{2+}(0.05$ $\%)$, followed by $\mathrm{Mg}^{2+}(0.03 \%)$; whereas the $\mathrm{Cl}^{-}$and $\mathrm{HCO}_{3}^{-}(0.80 \%$ and $0.35 \%$, respectively) dominates over the carbonate and sulphate anions of the total treated the soils.

\section{Soil Spectral Characteristics and its Correlation with Soil Properties}

The reflectance spectra showed prominent absorption features around 1400, 1900 and $2200 \mathrm{~nm}$ all of which are known to be related to features of free water $(\sim 1400$ and $\sim 1900 \mathrm{~nm})$ and clay lattice $\mathrm{OH}$ features $(\sim 1400$ and $\sim 2200 \mathrm{~nm}$ ) (Hunt 1982). Hence, these absorption bands would be more responsive towards the presence of salts in the soils; the sensitivity of which will depend upon the nature and amount of salts present in the soil samples. Farifteh et al. (2008) reported an increase in soil salinity induced changes in soil reflectance for wavebands higher than $1300 \mathrm{~nm}$, particularly in the water absorption bands (around 1400 and $1900 \mathrm{~nm}$ ). 
Table 1. Descriptive statistical parameters of soil chemical properties

\begin{tabular}{llrrrrrrrrr}
\hline \multicolumn{1}{c}{ Soil property } & \multirow{2}{*}{ N } & Min. & Max. & Mean & SD & Kurt & Skew & \multicolumn{3}{c}{ Percentile } \\
\cline { 8 - 11 } & & & & & & & & 25th & 50th & 75th \\
\hline $\mathrm{EC}_{\mathrm{e}}\left(\mathrm{mS} \mathrm{m}^{-1}\right)$ & 148 & 95.5 & 13065.0 & 3396.3 & 3335.6 & 0.6 & 1.1 & 708.0 & 1912.8 & 5633.8 \\
$\mathrm{pH}_{\mathrm{s}}$ & 148 & 6.9 & 10.0 & 7.9 & 0.9 & 0.3 & 1.2 & 7.3 & 7.6 & 8.0 \\
$\mathrm{SE} \mathrm{Cl}^{-}\left(\mathrm{mg} \mathrm{L}^{-1}\right)$ & 148 & 82.7 & 67330.0 & 8019.2 & 14832.8 & 7.1 & 2.6 & 454.9 & 909.9 & 5955.5 \\
$\mathrm{SE} \mathrm{HCO}_{3}^{-}\left(\mathrm{mg} \mathrm{L}^{-1}\right)$ & 148 & 145.2 & 43118.5 & 3456.9 & 8493.6 & 11.8 & 3.4 & 217.8 & 254.1 & 1197.7 \\
$\mathrm{SE} \mathrm{CO}_{3}^{2-}\left(\mathrm{mg} \mathrm{L}^{-1}\right)$ & 148 & 17.9 & 16493.4 & 1052.1 & 3284.8 & 14.9 & 3.9 & 17.9 & 35.7 & 196.4 \\
$\mathrm{SE} \mathrm{SO}_{4}^{2-}\left(\mathrm{mg} \mathrm{L}^{-1}\right)$ & 148 & 14.2 & 17589.9 & 1762.8 & 3638.6 & 8.1 & 2.9 & 45.4 & 585.3 & 1047.8 \\
$\mathrm{SE} \mathrm{Na}^{+}\left(\mathrm{mg} \mathrm{L}^{-1}\right)$ & 148 & 93.5 & 44000.0 & 10733.2 & 13219.5 & 0.4 & 1.3 & 962.5 & 4125.0 & 16637.5 \\
$\mathrm{SE} \mathrm{K}^{+}\left(\mathrm{mg} \mathrm{L}^{-1}\right)$ & 148 & 2.2 & 300.4 & 75.7 & 86.1 & 0.5 & 1.3 & 9.9 & 29.7 & 115.3 \\
$\mathrm{SE} \mathrm{Ca}^{2+}\left(\mathrm{mg} \mathrm{L}^{-1}\right)$ & 148 & 22.6 & 2348.9 & 500.9 & 554.2 & 3.2 & 2.0 & 186.8 & 354.7 & 498.1 \\
$\mathrm{SE} \mathrm{Mg}^{2+}\left(\mathrm{mg} \mathrm{L}^{-1}\right)$ & 148 & 1.3 & 1356.9 & 334.7 & 348.3 & 0.7 & 1.3 & 85.5 & 211.3 & 499.8 \\
\hline
\end{tabular}

\section{SE Saturation extract}

Effects of salts mixture $\left(\mathrm{NaCl}+\mathrm{Na}_{2} \mathrm{CO}_{3}+\right.$ $\mathrm{Na}_{2} \mathrm{SO}_{4}$ ) on air-dried soil reflectance spectra (Fig. 1) shows a similar pattern of spectra of a mixture of these three salts but the intensity of absorption peaks near the range of $1850-1900 \mathrm{~nm}$ wavelengths increase with the level of salinity.

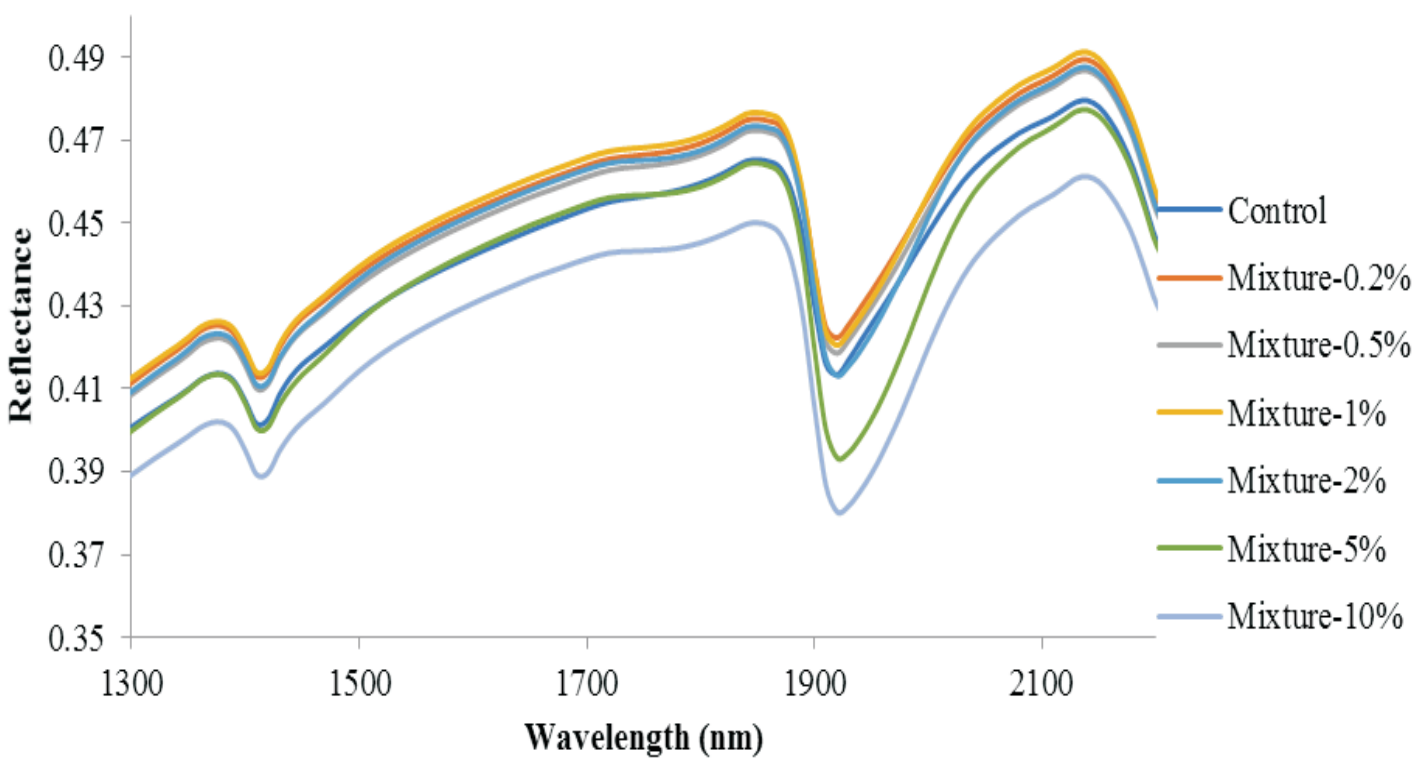

There was also a difference in reflectance of two type soil (Fig. 2). Soil-1 (Silty clay loam) show lower reflectance value than soil-2 (Silt loam). The mean soil reflectance spectra of different salt and soil types exhibited diagnostic absorption features at 1400 , 1900 , and $2200 \mathrm{~nm}$. A similar result was also reported by Wang et al. (2012) with the exception of the behaviour of $\mathrm{NaCl}$ spectra from 1300 to $2500 \mathrm{~nm}$. 


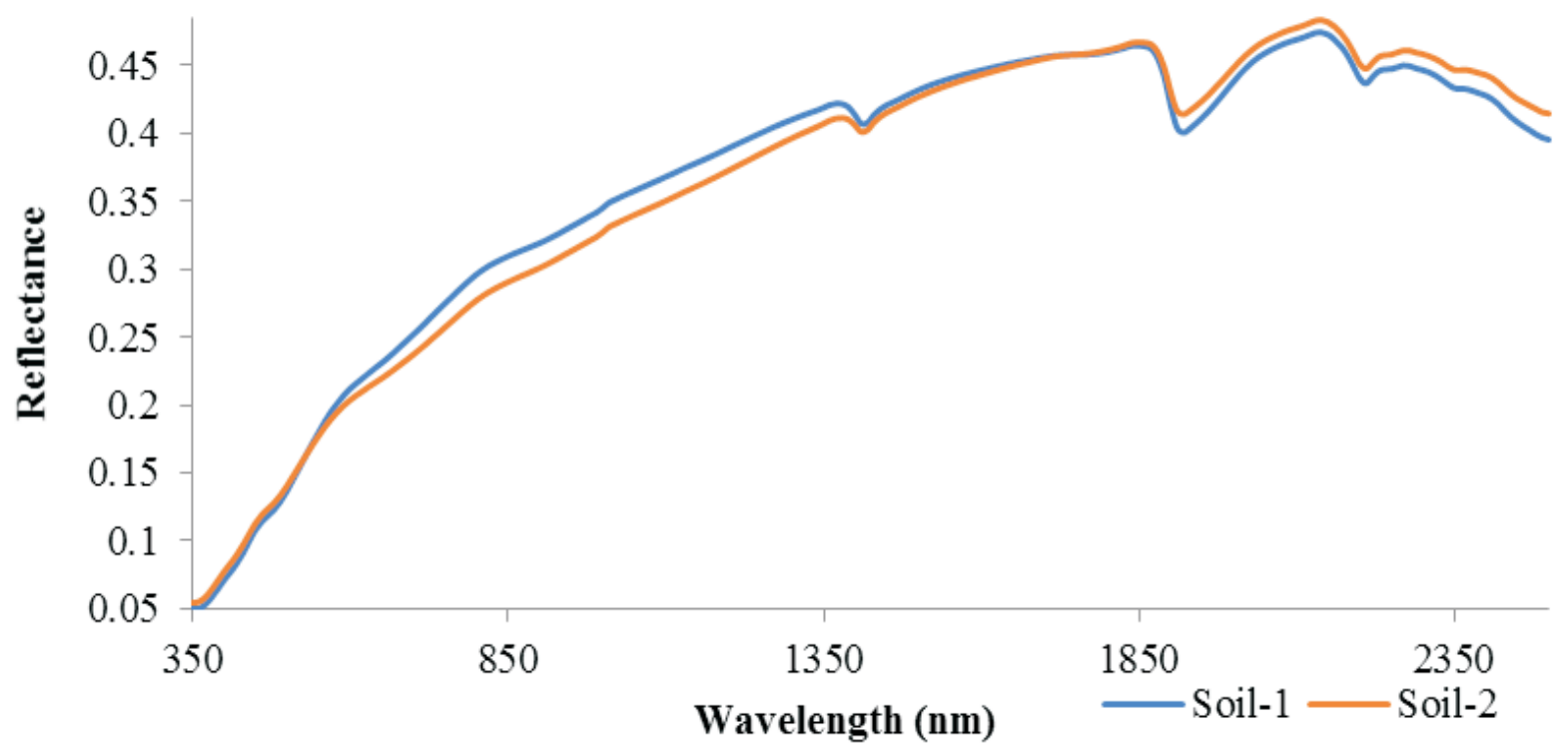

Fig. 2. Effects of soil types on air-dried soil reflectance spectra

The statistical correlation of soil chemical properties with first derivative soil reflectance data shows both positive and negative correlations at various wavelengths across the spectrum (Fig. 3). It indicates that saturated extract cations and anions showed a similar pattern of correlation at different wavelengths with $1^{\text {st }}$ derivative soil reflectance values as $\mathrm{EC}_{\mathrm{e}}$ (saturation extract EC). But the relatively high correlation of $\mathrm{EC}_{\mathrm{e}}$ with soil reflectance values was found between 1400 to $2220 \mathrm{~nm}$ which indicates that this region is highly sensitive to change in salinity levels. Srivastava et al. (2017) also reported that region of 1400 to $2450 \mathrm{~nm}$, correlated highly with different soil chemical properties of salt-affected soils of IndoGangetic plains of Haryana.

\section{Multiple Linear Regression (MLR) modelling of Hyperspectral Data}

Calibration

Salt-affected soil properties viz., $\mathrm{pH}_{\mathrm{s}}$ (saturation extract $\mathrm{pH}$ ), $\mathrm{EC}_{\mathrm{e}}$ (saturation extract $\mathrm{EC}$ ) saturated extract cations $\left(\mathrm{Na}^{+}, \mathrm{K}^{+}, \mathrm{Ca}^{2+}\right.$ and $\left.\mathrm{Mg}^{2+}\right)$ and anions $\left(\mathrm{Cl}^{-}\right.$and $\mathrm{SO}_{4}^{2-}$ , $\mathrm{CO}_{3}{ }^{2-}$ and $\mathrm{HCO}_{3}{ }^{-}$) were calibrated against the $1^{\text {st }}$ derivatives reflectance wavebands (Table 2). Very good calibrations of MLR models were obtained for $\mathrm{EC}_{\mathrm{e}}\left(\mathrm{r}^{2}-\right.$ 0.91, RMSE- 8.52), saturation extract $\mathrm{HCO}_{3}^{-}\left(\mathrm{r}^{2}-0.96\right.$, RMSE- 9.54), saturation extract $\mathrm{Na}^{+}\left(\mathrm{r}^{2}-0.88\right.$, RMSE21.11), saturation extract $\mathrm{Cl}^{-}\left(\mathrm{r}^{2}-0.93\right.$, RMSE- 17.16), saturation extract $\mathrm{CO}_{3}{ }^{2-}\left(\mathrm{r}^{2}-0.98, \mathrm{RMSE}-4.37\right)$ and $\mathrm{pHs}$ $\left(r^{2}-0.95\right.$, RMSE- 0.20). Higher regression coefficients (except for sulphate, calcium and magnesium cations) were achieved for all the MLR relations (Table 2). The poor calibration of MLR models for both saturation extract $\mathrm{Ca}^{2+}$ and $\mathrm{Mg}^{2+}$ may be attributed to the fact that there was no addition of the salt of calcium and magnesium and no replacement of these two divalent cations by monovalent sodium. Hence, the calibrated hyperspectral models for all the salinity and sodicity related parameters showed the good performance except calcium and magnesium cations in this study. 


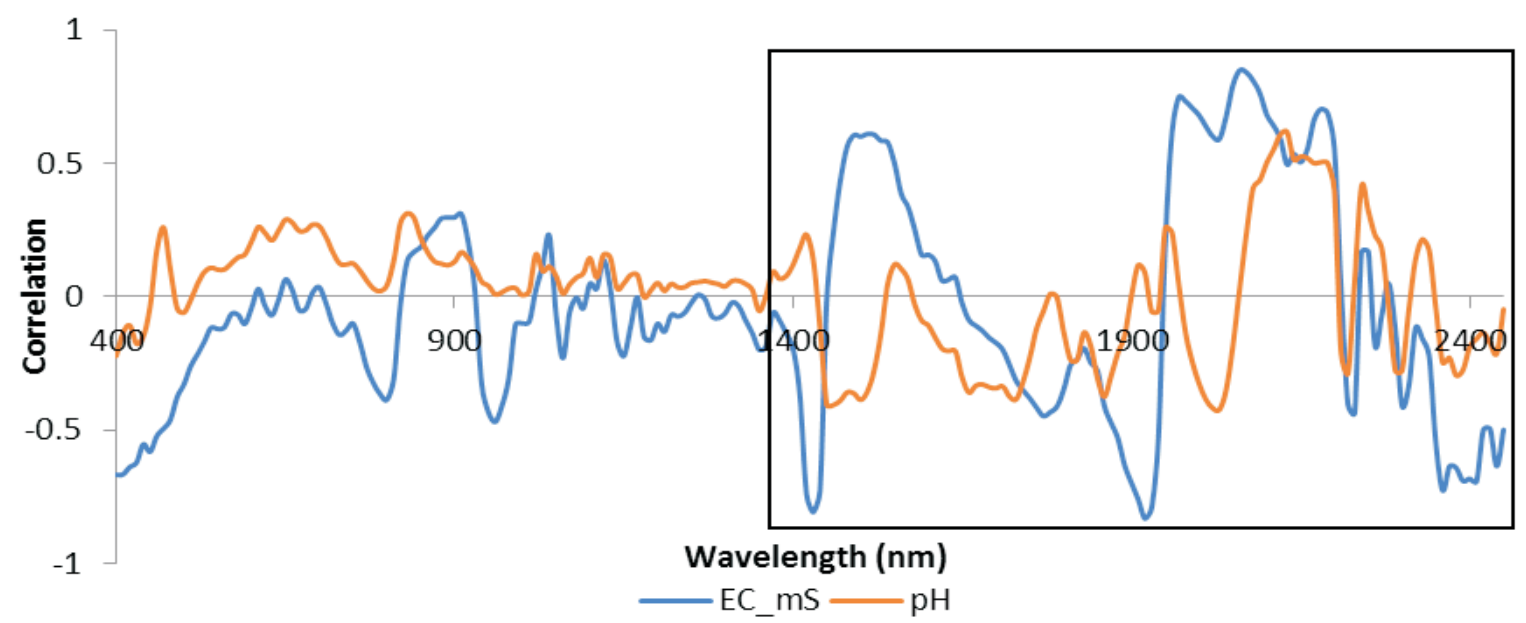

Fig. 3. Correlation of different soil salinity parameters with $1^{\text {st }}$ derivative soil reflectance between 400 and $2450 \mathrm{~nm}$ region

Table 2. Summary statistics for the spectral models developed by MLR

\begin{tabular}{lrrrrrrrrr}
\hline \multirow{2}{*}{ Soil parameters* } & No. of & \multicolumn{3}{c}{ Calibration set } & \multicolumn{5}{c}{ Validation set } \\
\cline { 7 - 11 } & Factors & $\mathrm{N}$ & $\mathrm{R}^{2}$ & RMSE & $\mathrm{N}$ & \multicolumn{1}{c}{ SD* } & $\mathrm{R}^{2}$ & RMSE & RPD \\
\hline $\mathrm{EC}_{\mathrm{e}}\left(\mathrm{mS} \mathrm{m}^{-1}\right)$ & 05 & 98 & 0.91 & 8.52 & 50 & 28.56 & 0.91 & 8.89 & 3.25 \\
$\mathrm{pH}_{\mathrm{s}}$ & 10 & 98 & 0.95 & 0.20 & 50 & 0.87 & 0.92 & 0.25 & 3.44 \\
$\mathrm{SE} \mathrm{Cl}^{-}\left(\mathrm{mg} \mathrm{L}^{-1}\right)$ & 07 & 98 & 0.93 & 17.16 & 50 & 63.77 & 0.90 & 20.16 & 3.16 \\
$\mathrm{SE} \mathrm{HCO}_{3}^{-}\left(\mathrm{mg} \mathrm{L}^{-1}\right)$ & 09 & 98 & 0.96 & 9.54 & 50 & 45.58 & 0.95 & 10.67 & 4.27 \\
$\mathrm{SE} \mathrm{CO}_{3}^{2-}\left(\mathrm{mg} \mathrm{L}^{-1}\right)$ & 13 & 98 & 0.98 & 4.37 & 50 & 27.98 & 0.96 & 5.55 & 5.04 \\
$\mathrm{SE} \mathrm{SO}_{4}^{2-}\left(\mathrm{mg} \mathrm{L}^{-1}\right)$ & 02 & 98 & 0.23 & 0.75 & 50 & 0.85 & 0.23 & 0.75 & 1.14 \\
$\mathrm{SE} \mathrm{Na}^{+}\left(\mathrm{mg} \mathrm{L}^{-1}\right)$ & 03 & 98 & 0.88 & 21.11 & 50 & 62.03 & 0.86 & 22.97 & 2.70 \\
$\mathrm{SE} \mathrm{K}^{+}\left(\mathrm{mg} \mathrm{L}^{-1}\right)$ & 06 & 98 & 0.86 & 1.76 & 50 & 4.77 & 0.86 & 1.85 & 2.58 \\
$\mathrm{SE} \mathrm{Ca}^{2+}\left(\mathrm{mg} \mathrm{L}^{-1}\right)$ & 02 & 98 & 0.52 & 7.24 & 50 & 10.77 & 0.52 & 7.47 & 1.44 \\
$\mathrm{SE} \mathrm{Mg}^{2+}\left(\mathrm{mg} \mathrm{L}^{-1}\right)$ & 02 & 98 & 0.37 & 7.48 & 50 & 9.24 & 0.26 & 8.02 & 1.15 \\
\hline
\end{tabular}

*Square root transformation was applied on all soil parameters except $\mathrm{pHs}$ (no transformation) and $\mathrm{SO}_{4}{ }^{2-}$

(Log transformation)

\section{Validation}

The validation of the model using the independent dataset for all the parameters was evaluated based on the performance of validation indices of $r^{2}$, RMSE and RPD (Table 2). The $\mathrm{r}^{2}$ indicates the percentage of the variance in the dependent variable that is accounted for by the independent variables. The RMSE estimates the variation of predicted values around observed values, and as it approaches zero, the prediction performance of the equation increases. The
RPD is the factor, by which the prediction accuracy has been increased compared to using the mean composition for all samples. Chang et al. (2001) grouped the prediction quality of soil properties using VNIR spectroscopy into three categories based on RPD values in the ranges of $>2.0,1.4-2.0$, and $<1.4$ to indicate excellent, acceptable and poor predictions, respectively. They suggested that the predictions in the middle category could be improved using different calibration strategies, but the properties in the poor category may not be reliably predicted using reflectance spectroscopy. 
The application of calibration models for prediction of soil attributes in the independent validation datasets also resulted in high $r^{2}$ for all the attributes except soil saturation extract sulphate, calcium and magnesium cation (Table 2). The calibration models obtained for soil sulphate $\left(r^{2}-0.23\right)$, saturation extract calcium $\left(r^{2}-0.52\right)$ and magnesium $\left(r^{2}-0.37\right)$ with $1^{\text {st }}$ derivative soil reflectance data did not show good relationship due to low variability in the datasets. The high RPD values (>2.0) obtained for $\mathrm{EC}_{\mathrm{e}}, \mathrm{pHs}$, saturated extract $\mathrm{Na}^{+}, \mathrm{K}+, \mathrm{Cl}^{-}, \mathrm{HCO}_{3}^{-}$and $\mathrm{CO}_{3}{ }^{2-}$ indicate that these properties can be reliably predicted from the spectral models (Fig. 5) whereas the spectral model of saturation extract $\mathrm{SO}_{4}^{2-}$ (RPD - 1.14) needs further improvement with larger datasets. The $\mathrm{CO}_{3}{ }^{2-}$ spectral model showed the best performance for all the three validation indices (Fig. 4). Relatively greater variability in prediction at higher concentrations than lower concentrations of different soil salinity variables (Fig. 5) may be because of error in the laboratory analytical methods rather than genuine lack of predictive power of the spectral models. Shepherd and Walsh (2002) observed that increased analytical error at higher concentrations could be expected because of greater variability in amounts of ion extracted and the need for an increasing number of dilutions.

Best regression spectral models of SAS parameters were presented in table 3. Among the cation $\mathrm{Na}^{+}$and $\mathrm{K}^{+}$models explained the variability more than $85 \%$ with significant water-absorbing central waveband at 2200 and $1900 \mathrm{~nm}$, whereas, among anions carbonate and bicarbonate models contributed more than $95 \%$ variability due to variation among the data set. $\mathrm{pH}_{\mathrm{s}}$ and $\mathrm{EC}_{\mathrm{e}}$ models significantly $(p<0.05)$ fitted with more than 0.91 coefficient of determination value. But other sulphates, calcium and magnesium models fitted with a poor coefficient of determination value (Table 2 ) due to less replacement from soil solid phase to soil solution by a monovalent sodium ion.

Table 3. Regression spectral models of transformed SAS parameters with their significant waveband

\begin{tabular}{|c|c|c|c|}
\hline $\begin{array}{l}\text { SAS Parameter } \\
\text { (Y) }\end{array}$ & Multiple regression equation & $\mathbf{R}^{2}$ & $\mathbf{F}$ \\
\hline $\mathrm{pH}_{\mathrm{s}}$ & $\begin{array}{l}Y=15.25+4.78(\lambda 400)-12.29(\lambda 1920)-11.79(\lambda 2040)+11.11 \\
(\lambda 1990)+8.12(\lambda 1910)+5.62(\lambda 2400)+4.25(\lambda 740)-12.75 \\
(\lambda 450)+8.66(\lambda 540)-6.16(\lambda 890)\end{array}$ & 0.95 & $154.47^{* *}$ \\
\hline $\begin{array}{l}\mathrm{EC}_{\mathrm{e}} \\
\left(\mathrm{mS} \mathrm{m}^{-1}\right)\end{array}$ & $\begin{array}{l}Y=49.62-11.89(\lambda 1950)+4.90(\lambda 2350)-1.19(\lambda 2060)-3.10 \\
(\lambda 2440)+10.63(\lambda 1940)\end{array}$ & 0.91 & $193.29^{* *}$ \\
\hline $\begin{array}{l}\mathrm{SE} \mathrm{HCO}_{3}^{-} \\
\left(\mathrm{mg} \mathrm{L}^{-1}\right)\end{array}$ & $\begin{array}{l}Y=79.45-6.44(\lambda 2060)+7.64(\lambda 2360)-5.34(\lambda 1450)-7.86 \\
(\lambda 2340)-11.17(660)+3.51(\lambda 2410)+10.08(\lambda 1480)+13.06 \\
(\lambda 680)-3.82(\lambda 910)\end{array}$ & 0.96 & $214.20 * *$ \\
\hline $\begin{array}{l}\mathrm{SE} \mathrm{CO}_{3}^{2-} \\
\left(\mathrm{mg} \mathrm{L}^{-1}\right)\end{array}$ & $\begin{array}{l}Y=126.51+3.54(\lambda 1890)+7.82(\lambda 2360)-4.39(\lambda 1420)-4.76 \\
(\lambda 2340)+5.99(\lambda 1490)+1.66(\lambda 2440)-4.76(\lambda 1820)+9.23 \\
(\lambda 1850)-6.99(\lambda 1870)-9.68(\lambda 2110)-3.08(\lambda 1020)+3.03 \\
(\lambda 1290)+1.98(\lambda 1690)\end{array}$ & 0.98 & $280.65^{* *}$ \\
\hline $\begin{array}{l}\mathrm{SE} \mathrm{Na}^{+} \\
\left(\mathrm{mg} \mathrm{L}^{-1}\right)\end{array}$ & $Y=171.50+6.47(\lambda 2350)-2.75(\lambda 2080)-4.34(\lambda 2450)$ & 0.88 & $224.20^{* *}$ \\
\hline $\begin{array}{l}\mathrm{SE} \mathrm{K}^{+} \\
\left(\mathrm{mg} \mathrm{L}^{-1}\right)\end{array}$ & $\begin{array}{l}Y=3.94-0.73(\lambda 400)+3.48(\lambda 2350)-13.33(\lambda 2170)+14.69 \\
(\lambda 2280)+3.96(\lambda 1880)-8.34(\lambda 2220)\end{array}$ & 0.86 & $94.74 * *$ \\
\hline
\end{tabular}

*Square root transformation was applied on all soil parameters except $\mathrm{pHs}$ 


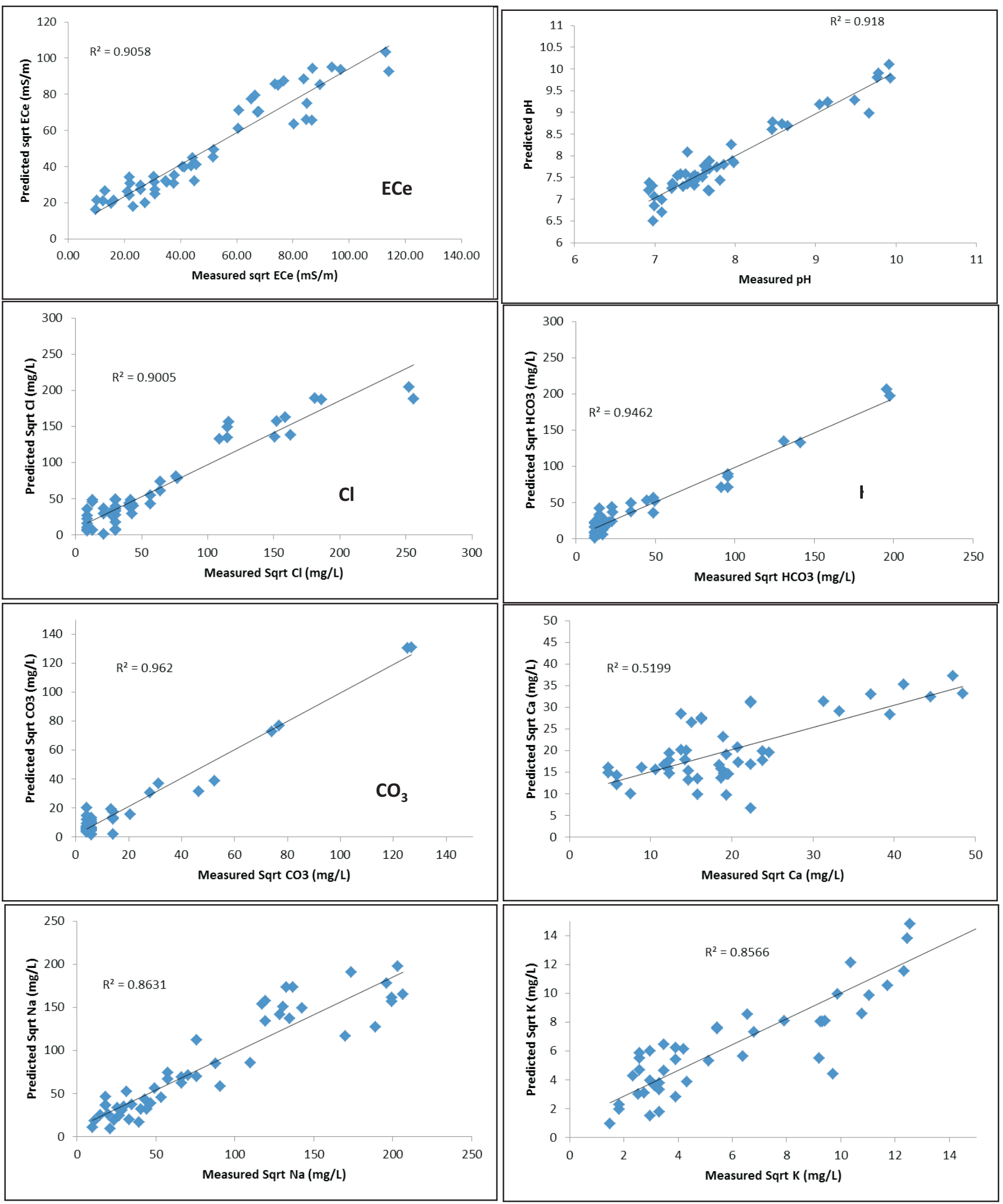

Fig. 4. Scatter plot of measured and predicted values (all in square root transformation except $\mathrm{pH}_{\mathrm{s}}$ - no transformation and $\mathrm{SO}_{4}^{2-}-\mathrm{Log}$ transformation) of salt-affected properties in validation datasets. 


\section{Conclusion}

The VNIR spectroscopy can be successfully used for rapid prediction of percentage chloride, carbonate and bicarbonate of sodium salts in saline/sodic soils as well as the type of salt present in the soil. Saline soils have diagnostic absorption features in the VNIR parts of the spectrum that might be attributed to the presence of moisture in the hygroscopic salt minerals. The hyperspectral models of $\mathrm{EC}_{\mathrm{e}}, \mathrm{pH}_{\mathrm{s}}$ and other salinity related attributes fed with large number of dataset having broad range of salinity were able to capture more than $85 \%$ of the variability except sulphate, calcium and magnesium. With the growing interest on high resolution hyperspectral satellite data applicability; our findings regarding rapid assessment of soil salinity and sodicity through hyperspectral models are encouraging as it might assist in real time monitoring of salinity over the spatio-temporal context and also helps to enrich spectral library; enabling the farmers to cope up with this degradation in a better way. We realize, however, that the model we obtained is based on controlled laboratory experiments and have not been validated for field applications, and therefore deserves further field investigation.

\section{Acknowledgements}

The authors sincerely acknowledge the help and support provided by the Director, ICAR-CSSRI, Karnal, Director, ICAR-NBSS \& LUP, Nagpur, and financial assistance received from Indian Council of Agricultural Research, New Delhi and Department of Science and Technology (DST). Thanks are also due to Dr. Parveen Kumar, Dr. S. Chatterji and other PME members of the institutes (PME No.-Research Article/117/2020) for moral support and help to proceed with this work.

\section{References}

Ben-Dor, E., Irons, J.R. and Epema, G.F. (1999). Soil reflectance. In 'Remote Sensing for the Earth Sciences, Manual of remote sensing'. Third Edition. (Eds. A.N. Rencz) pp.111-188. (John Wiley \& Sons : New York).
Chang, C.W., Laird, D.A., Mausbach, M.J. and Hurburgh, C.R. (2001). Near-infrared reflectance spectroscopy-principal components regression analyses of soil properties. Soil Science Society of America Journal 65, 480-490.

Cheng, K.L.U. and Bray, R.H. (1951). Determination of calcium and magnesium in soil and plant material. Soil Science 72, 449-458.

Chesnin, L. and Yien, C.H. (1950). Turbidimetric determination of available sulphates. Soil Science Society of America Journal 15, 149-151.

Csillag, F., Pasztore, L. and Biehl, L.L. (1993). Spectral band selection for characterization of salinity status of soils. Remote Sensing of Environment 43, 231-242.

Farifteh, J., Bouma, A. and Van Der Meijde, M. (2004). A new approach in the detection of salt affected soils, integrating surface and sub-surface measurements. In 'Conference Proceedings "Near Surface 2004" - $10^{\text {th }}$ EAGE (European Association of Geoscientists and Engineers), European Meeting of Environmental and Engineering Geophysics'.

Farifteh, J., Van Der Meer, F., Atzberger, C. and Carranza, E.J.M. (2007). Quantitative analysis of salt affected soil reflectance spectra: a comparison of two adaptive methods (PLSR and ANN). Remote Sensing of Environment 110, 59-78.

Farifteh, J., Van Der Meer, F., Van Der Meijde, M. and Atzberger, C. (2008). Spectral characteristics of salt-affected soils: a laboratory experiment. Geoderma 145, 196-206.

Howari, F.M., Goodell, P.C., Miyamoto, S. and Penn, B. (2000). Spectral properties of treated silty clay loam and fine sandy loam with gypsum, halite and their mixtures. In 'Remote Sensing 2000'. pp. 2. (Black land Res. and Ext. Center, TX).

Hunt, G.R. (1982). Spectroscopic properties of rocks and minerals. In 'Handbook of Physical Properties of Rocks'. (Eds. R. S. Carmichael) pp. 295-385. (CRC Press, Boca Raton: Florida). 
Metternicht, G.I. and Zinck, J.A. (1997). Spatial discrimination of salt and sodium affected soil surfaces. International Journal of Remote sensing 18, 2471-2486.

Metternicht, G.I. and Zinck, J.A. (2003). Remote sensing of soil salinity: potentials and constraints. Remote Sensing of Environment 85, $1-20$.

Richards, L.A. (1954). Diagnosis and improvement of saline and alkali soils. In 'USDA Agriculture Handbook No.60', (Washington: DC).

Shepherd, K.D. and Walsh, M.G. (2002). Development of reflectance spectral libraries for characterization of soil properties. Soil Science Society of America Journal 66, 988-998.

Sinha Yagani, Srivastava, R., Jagdish Prasad, Nagaraju, M.S.S., Tiwary, P., Nasre, R.A., Wakode, R. (2017). Establishing relationship between saturated paste electrical conductivity (ece) and soil: water electrical conductivity (EC1:2) in some swell-shink soils of Nagpur district Maharashtra. Agropedology 27, 181-186.

Srivastava, R., Sarkar, D., Mukhopadhayay, S.S., Sood, A., Singh, M., Nasre, R.A. and Dhale, S.A. (2015). Development of hyperspectral model for rapid monitoring of soil organic carbon under precision farming in the Indo-Gangetic plains of Punjab, India. Journal of the Indian Society of Remote Sensing 43, 751-759.

Srivastava, R., Sethi, M., Yadav, R.K., Bundela, D.S., Singh, M., Chattaraj, S., Singh, S.K., Nasre, R.A., Bishnoi, S. R., Dhale, S., Mohekar, D.S. and Barthwal, A.K. (2017). Visible-near infrared reflectance spectroscopy for rapid characterization of salt-affected soil in the Indo-Gangetic plains of Haryana, India. Journal of the Indian Society of Remote Sensing 45, 307-315.

Van, R.L.P. (1993). Procedures for soil analysis. Technical paper No. 9. Wangeningen: International Soil Reference and Information Centre (ISRIC).

Volkan, B.A., Van, H.M., Akbas, F., Durak, A. and Hively, W.D. (2010). Visible-near infrared reflectance spectroscopy for assessment of soil properties in a semi-arid area of Turkey. Journal of Arid Environments 7, 229-238.

Wang, Q., Pingheng, L. and Chen, X. (2012). Modeling salinity effects on soil reflectance under various moisture conditions and its inverse application: A laboratory experiment. Geoderma 170, 103-111.

Received: January, 2018

Accepted: May, 2019 